BMJ Open Sport \& Exercise Medicine

\title{
Water intake after dehydration makes muscles more susceptible to cramp but electrolytes reverse that effect
}

\author{
Wing Yin Lau, ${ }^{1}$ Haruyasu Kato, ${ }^{2}$ Kazunori Nosaka ${ }^{\circledR}$
}

To cite: Lau WY, Kato $\mathrm{H}$, Nosaka K. Water intake after dehydration makes muscles more susceptible to cramp but electrolytes reverse that effect. BMJ Open Sport \& Exercise Medicine 2019;5:e000478. doi:10.1136/ bmjsem-2018-000478

Accepted 31 January 2019

\section{Check for updates}

(C) Author(s) (or their employer(s)) 2019. Re-use permitted under CC BY-NC. No commercial re-use. See rights and permissions. Published by BMJ.

${ }^{1}$ Centre for Exercise and Sports Science Research, School of Medical and Health Sciences, Edith Cowan University, Joondalup, Western Australia, Australia

${ }^{2}$ Department of Sport and Wellness, Rikkyo University Niiza Campus, Niiza, Japan

Correspondence to Professor Kazunori Nosaka; k.nosaka@ecu.edu.au

\begin{abstract}
Objective No previous study has compared water and oral rehydration solution (ORS) intake after dehydration induced by exercise in the heat for the effect on muscle cramps. The present study tested the hypothesis that water ingestion after dehydration would increase muscle cramp susceptibility, but this would be prevented by ORS ingestion.
\end{abstract}

Methods Ten men performed two bouts of downhill running (DHR; $-5 \%)$ in the heat $\left(35^{\circ} \mathrm{C}-36^{\circ} \mathrm{C}\right)$ until their body mass was reduced by $2 \%$. Ten minutes after DHR, either spring water or electrolyte water similar to ORS $\left(0 \mathrm{~S}-1^{\circledR}\right)$ was ingested in a counter-balanced order on two different days separated by a week. Muscle cramp susceptibility was assessed by a threshold frequency (TF) of electrical train stimulation to induce cramp before, immediately after (0), and 30 and 60 min after the ingestion. Blood samples were taken before, immediately and $80 \mathrm{~min}$ after DHR to measure serum electrolyte concentrations.

Results Muscle cramp susceptibility assessed by TF did not change from baseline to immediately after DHR for both conditions (water: $24.6 \pm 2.1 \mathrm{~Hz}, 0 \mathrm{~S}-1^{\circledR}: 24.7 \pm$ $1.4 \mathrm{~Hz}$ ). TF decreased after water intake by $4.3 \mathrm{~Hz}$ (30 min) and $5.1 \mathrm{~Hz}$ (60 min post-ingestion), but increased after OS$1^{\circledR}$ intake by 3.7 and $5.4 \mathrm{~Hz}$, respectively. Serum sodium and chloride concentrations decreased after water intake but maintained after OS $-1^{\circledR}$ intake.

Conclusion These results suggest that water intake after dehydration makes muscles more susceptible to electrical simulation-induced muscle cramp, probably due to dilution of electrolytes, and when OS- $1^{\circledR}$ is consumed, the susceptibility to muscle cramp decreases.

\section{INTRODUCTION}

Exercise-associated muscle cramp (EAMC) is a painful, involuntary muscle contraction induced during or after exercise. ${ }^{1-4}$ EAMC can affect sports performance, ${ }^{56}$ thus prevention of EAMC is necessary. To do so, the aetiology of EAMC should be considered, but the mechanisms underpinning EAMC are not necessarily clear, although neural theory and dehydration-electrolytes theory have been mainly proposed. ${ }^{2} 37$ It has been documented, in recent studies, that EAMC stems from an imbalance between excitatory drive

\section{Summary box}

The new findings of the present study are as follows: (1) water intake after $2 \%$ dehydration induced by downhill running in the heat increased muscle cramp susceptibility, but (2) ingestion of fluid containing electrolytes such as sodium, potassium and chloride, and glucose (similar to oral rehydration solution) after the dehydration made muscles more immune to cramp.

- These results suggest that to prevent exercise-associated muscle cramp, it is better to intake fluid containing electrolytes. However, further studies are necessary to examine what kind of and how much electrolytes should be contained in the fluid to prevent muscle cramp.

from muscle spindles and inhibitory drive from Golgi tendon organs to the alpha motor neurons, rather than dehydration or electrolytes deficits. $^{2} 7$

In association with the dehydration-electrolytes theory, several studies have reported that dehydration does not affect muscle cramp. ${ }^{8-10}$ Miller et a ${ }^{\ominus}$ did not find changes in threshold frequency (TF) of electrically induced muscle cramp after $3 \%$ dehydration. It should be noted that they reported an increase in serum sodium concentration from baseline $(138.6 \pm 0.2 \mathrm{mmol} / \mathrm{L})$ to post-dehydration (145.1 $\pm 0.5 \mathrm{mmol} / \mathrm{L})$. Similarly, Braulick et $a l^{10}$ reported an increase in serum sodium concentration in 3\%-5\% dehydrated condition $(149.5 \pm 1.8 \mathrm{mmol} / \mathrm{L})$ in comparison to euhydrated condition $(141.9 \pm 3.1 \mathrm{mmol} / \mathrm{L})$ and found no difference in TF between the conditions. The increases in serum sodium concentration suggest that body water loss was more than sodium loss in these studies. Hyponatremia is a condition in which sodium concentration is less than $135 \mathrm{mmol} / \mathrm{L}$, and one of its typical symptoms is muscle cramp. ${ }^{11}$ Thus, it is possible that water intake after dehydration dilutes sodium and other electrolytes in the blood and extracellular fluid in the body and could decrease sodium concentration, inducing muscle cramp. 
Our pilot study showed that no significant changes in $\mathrm{TF}$ were evident immediately after downhill running (DHR) in the heat to induce $1 \%$ or $2 \%$ loss of body mass by sweat, but when water $(600 \mathrm{~mL}$ for $1 \%$ and $1200 \mathrm{~mL}$ for $2 \%$ dehydration condition) was ingested immediately after DHR, a significant decrease in TF was observed at 30 and 60 min later. Interestingly, when no water was ingested immediately after DHR, no such decrease in TF was found at $30 \mathrm{~min}$ later, but ingesting water at this time point, a decrease in $\mathrm{TF}$ was evident at $30 \mathrm{~min}$ later. These suggest that water intake in dehydrated condition may increase muscle cramp susceptibility, probably due to dilution of electrolytes in the body. Jung et $a l^{12}$ reported that half a tablespoon of sodium chloride added to a litre of carbohydrate-electrolyte beverage (Gatorade) taken before and during exercise in a hot environment, delayed onset of EAMC and prolonged exercise time, when compared with hypohydration condition in which no fluid was taken. However, no previous study has investigated the effect of oral rehydration solution (ORS) intake after dehydration on EAMC.

Therefore, the present study investigated the hypothesis that ingestion of spring water after $2 \%$ dehydration induced by DHR in the heat would decrease TF, but no changes in TF would be observed after ingestion of ORS. Previous studies have used TF of the abductor hallucis muscle,${ }^{13-15}$ or the plantar flexors, ${ }^{16}$ and used a decrease in $\mathrm{TF}$ as a marker of increased muscle cramp susceptibility. In the present study, a TF measure of calf muscles was established and used to assess muscle cramp susceptibility after DHR in the heat, and OS- $1^{\circledR}$ (Otsuka Pharmaceutical Factory, Japan) was used as ORS.

\section{METHODS}

\section{Experimental design}

This study used a cross-over study design to compare between water and OS- $1^{\circledR}$ conditions for changes in TF of electrical stimulation to induce calf muscle cramp before and after DHR in the heat that resulted in $2 \%$ loss of body mass by increased sweating, using 10 healthy young men. The two conditions (water, OS- ${ }^{\circledR}$ ) were separated by a week in a counter-balanced order (five participants: water condition first, five participants: OS- $1^{\circledR}$ condition first).

OS- $1^{\circledR}$ contains sodium $(2970 \mathrm{mg} / \mathrm{L})$, potassium $(794$ $\mathrm{mg} / \mathrm{L})$, magnesium $(25 \mathrm{mg} / \mathrm{L})$, chloride (1801 mg/L), glucose (18 $300 \mathrm{mg} / \mathrm{L})$ and others (eg, phosphorus). For the water condition, a commercially available spring water was used, which contains a small amount of sodium (2 $\mathrm{mg} / \mathrm{L})$, potassium $(0.5 \mathrm{mg} / \mathrm{L})$, magnesium $(18 \mathrm{mg} / \mathrm{L})$, chloride $(1.2 \mathrm{mg} / \mathrm{L})$, and calcium $(39 \mathrm{mg} / \mathrm{L})$.

In addition to TF, serum sodium, potassium, magnesium and chloride concentrations were measured before, immediately after and $80 \mathrm{~min}$ after DHR (figure 1). Haematocrit (Hct), haemoglobin (Hb) and serum osmolality were assessed as dehydration parameters, and heart rate (HR), rate of physical exertion (RPE), thermal

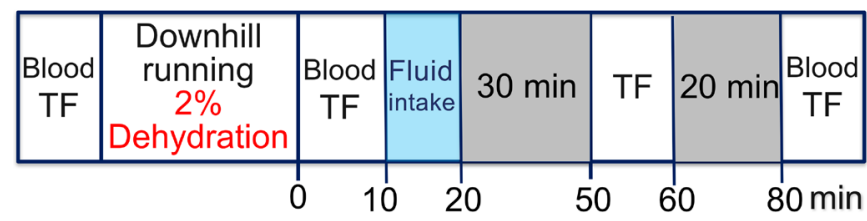

\begin{tabular}{|c|c|c|}
\hline \multirow{4}{*}{$\begin{array}{l}\text { - Heart rate } \\
\text { - RPE } \\
\text { - Thermal sensation } \\
\text { (every } 5 \text { min) } \\
\text { - Tympanic temperature } \\
\text { - Blood pressure } \\
\text { - Body mass } \\
\text { (20 min + every } 10 \mathrm{~min} \text { ) }\end{array}$} & $\begin{array}{l}2 \% \text { of } \\
\text { body } \\
\text { mass }\end{array}$ & \multirow{5}{*}{$\begin{array}{l}\text { Threshold frequency (TF) } \\
\text { Dehydration parameters } \\
\text { - Hct, Hemoglobin } \\
\text { - Serum osmolality } \\
\text { Serum electrolytes } \\
\text { - Sodium } \\
\text { - Potassium } \\
\text { - Magnesium } \\
\text { - Chloride } \\
\end{array}$} \\
\hline & Water & \\
\hline & & \\
\hline & \multirow{3}{*}{$\begin{array}{c}\text { Counter } \\
\text { balanced } \\
\text { order } \\
(1 \mathrm{wk})\end{array}$} & \\
\hline Measures during DHR & & \\
\hline & & \\
\hline
\end{tabular}

Figure 1 Study design and the time course of measurements taken in the study. Before DHR, blood sample was taken to assess Hct, haemoglobin and serum osmolality, and to measure serum sodium, potassium, magnesium and chloride concentrations, and TF of electrical train stimulation was measured as an indicator of muscle cramp susceptibility. During DHR, heart rate was monitored continuously, RPE and thermal sensation were recorded every $5 \mathrm{~min}$, and tympanic temperature, blood pressure and body mass were measured after the first 20 min followed by every 10 min during DHR. Immediately after DHR, blood sample was taken for the analyses shown above, and TF was measured again. Then, the participants were instructed to ingest spring water or OS $-1^{\circledR}$ in 10 min for the amount equivalent to the volume that they lost during DHR. TF was measured at 30 and $60 \mathrm{~min}$ after the water or OS- $1^{\circledR}$ ingestion (50 and 80 min after DHR), and blood sample was taken at 60 min after the ingestion (80 min after DHR). DHR, downhill running; Hct, haematocrit; RPE, rate of physical exertion; TF, threshold frequency.

sensation, tympanic temperature, blood pressure and body mass were measured during DHR.

\section{Participants}

This study was approved by the Institutional Human Research Ethics Committee and complied with the Declaration of Helsinki. All participants signed an informed consent form and completed a medical questionnaire before participating in the study. It was confirmed that all of them had good health and fitness and did not have any pathological conditions such as peripheral neuropathy and liver cirrhosis that are known to cause muscle cramps. They did not have current or previous (in 2 years at least) lower limb injuries. Their mean \pm SD (range) age, height and body mass were $25.0 \pm 2.7$ (22-31) years, $173.7 \pm 6.4(165-184) \mathrm{cm}$ and $74.0 \pm 12.0(57.2-89.3) \mathrm{kg}$, respectively. Using the data from our pilot study showing that TF to induce muscle cramp for normal condition (no dehydration) was $21.3 \pm 1.5 \mathrm{~Hz}$, and $\mathrm{TF}$ decreased by $15 \%(3 \mathrm{~Hz})$ after water intake, it was estimated that nine participants were necessary. Considering a potential dropout and estimation error, 10 participants were recruited for this study. 
All participants were instructed to refrain from any strenuous exercise for 1 week before the study. They were asked to consume $600 \mathrm{~mL}$ of spring water at 2 hours before coming to the laboratory, and refrain from any food intake for at least 2 hours before each exercise session. The food intake before the first session was recorded by each participant, and he was asked to have the same food before the second session. The participants were requested not to change their lifestyle and diet, not to take any anti-inflammatory drugs or nutritional supplements and not to perform any strenuous exercise during the week between the sessions.

\section{Threshold frequency}

The participants were familiarised with the electrical stimulation to induce muscle cramp in a familiarisation session at 1 week before the first experimental session. Here, we checked whether muscle cramp was induced by the stimulation. Electrical train stimulation was delivered to calf muscles of the kicking (dominant) leg by using a portable electrical stimulator (Compex 2, Compex Medical, Switzerland). To deliver the stimulation, one electrode (cathode) was placed over the tibialis posterior nerve in the popliteal fossa, and the other electrode (anode) was placed at the ankle between the end of posterior soleus muscle and tibialis tendon. The locations of the electrodes were marked by a semi-permanent marker to ensure the consistent electrode placement between measures in the same day and between sessions separated by a week.

Each participant was lying prone on a massage bed, and the instep was placed on the bed, which kept the ankle joint in a plantar-flexed position. Each stimulation consisted of $0.5 \mathrm{~s}$ duration of rise time and $2.0 \mathrm{~s}$ bursts of stimuli of $300 \mu$ s duration. The stimulation started at a frequency of $10 \mathrm{~Hz}$, and two stimulations were given at this frequency during which the stimulation intensity was increased to a preset level $(18-60 \mathrm{~mA})$. The stimulation intensity for each participant was determined in the familiarisation session, and the intensity was set for the baseline TF to be between 22 and $26 \mathrm{~Hz}$. The intensity was the same for the rest of the measurements and between the sessions. Thereafter, the stimulation frequency was automatically increased by $2 \mathrm{~Hz}$ every $30 \mathrm{~s}$ until muscle cramp was induced. The muscle cramp was identified by a visibly taut muscle, pain and calf muscle contraction and also reported by the participant. As soon as muscle cramp was confirmed, the investigator provided passive dorsiflexion of the foot to release the cramp. The TF at which cramp was induced was recorded for further analysis.

The test-retest reliability of the TF to induce muscle cramp was assessed between two baseline measurements within the same day separated by $15 \mathrm{~min}$ and between days separated by 24 hours. The coefficient of variation was $3 \%$ for the two measures in the same day as well as the two different days, and SE of the measurement was $0.8 \mathrm{~Hz}$ for the same day and $0.6 \mathrm{~Hz}$ for the different days.

\section{Downhill running}

The participants performed two bouts of DHR (slope: $5 \%$ ) in a climate chamber set at $35^{\circ} \mathrm{C}-36^{\circ} \mathrm{C}$ and $27 \%-34 \%$ relative humidity until their body mass was decreased by $2 \%$. To increase sweating, all participants wore a sauna suit for the upper body. The running velocity was between 7.5 and $9.7 \mathrm{~km} / \mathrm{h}$ depending on the participants, and the velocity was changed on the condition of each participant such that the velocity was reduced when the participant struggled to maintain the velocity. The body mass was measured by a scale (Mettler Toltdo ID1, Columbus, $\mathrm{OH}$, USA), when the participants stopped after the first 20 min of DHR, took off all clothes and wiped sweat. This was repeated every 10 min thereafter until the body mass was decreased by $2 \%$ of the baseline body mass of each participant.

HR, RPE and thermal sensation were measured before, then every 5 min during DHR. A HR monitor (Model S610i; Polar Electro Oy, Finland) was used to record HR during DHR, and the 6-point to 20-point Borg Scale ${ }^{17}$ was used for RPE. Thermal sensation was assessed by a thermal sensation scale (eight-point scale ranging from unbearably cold [0] to unbearable hot [8]). ${ }^{18}$ Blood pressure and tympanic temperature were measured by an automatic sphygmomanometer and a temperature probe, respectively, before, after the first $20 \mathrm{~min}$ and every $10 \mathrm{~min}$ during DHR, and at the end of DHR.

\section{Blood sampling and analyses}

Approximately $8 \mathrm{~mL}$ of blood was drawn by a standard venepuncture technique from the antecubital vein before, immediately after and $80 \mathrm{~min}$ after DHR. Using a portion of the blood sample $(1.5 \mathrm{~mL})$, Hct and $\mathrm{Hb}$ were measured by a capillary method and a HemoCue ( $\mathrm{Hb}$ 201 System, Sweden), respectively. The rest of the blood was centrifuged for $10 \mathrm{~min}$ at $3000 \mathrm{rpm}$ to obtain serum to be analysed for electrolyte concentrations of sodium, chlorine, potassium and magnesium, and osmolality.

\section{Statistical analysis}

Two-way repeated measures analysis of variance (ANOVA) was used to compare the changes in the TF between conditions (water vs OS- $1^{\circledR}$ ) before, immediately after, and 50 and 80 min after DHR. Changes in other measures (body mass, HR, RPE, thermal sensation, blood pressure, tympanic temperature) during DHR, and changes in the blood dehydration parameters (Hct, $\mathrm{Hb}$, serum osmolality), serum electrolyte concentrations (sodium, potassium, magnesium, chloride) before, immediately after and $80 \mathrm{~min}$ after DHR were also compared between conditions using two-way repeated measures ANOVA. When the ANOVA showed a significant time effect and/or interaction effect, a Tukey's post-hoc test was performed for multiple comparisons. Statistical significance was set at $\mathrm{p}<0.05$, and all data were presented as mean \pm SD. 
Table 1 Changes (mean \pm SD) in Hct and $\mathrm{Hb}$, and serum concentration of sodium, potassium, magnesium and chloride before (pre), and immediately (0) and 80 min following DHR for the spring water (water) and electrolyte water (OS-1 $1^{\circledR}$ ) intake at 10 min after DHR

\begin{tabular}{|c|c|c|c|c|c|}
\hline & & Pre & 0 & 80 & ANOVA \\
\hline \multirow{2}{*}{$\begin{array}{l}\text { Hct } \\
(\%)\end{array}$} & Water & $47.3 \pm 2.7$ & $48.2 \pm 2.1$ & $47.6 \pm 1.8$ & $F=2.37$ \\
\hline & OS-1 & $46.3 \pm 1.6$ & $47.8 \pm 2.0^{*}$ & $45.6 \pm 1.1$ & $\mathrm{p}=0.12$ \\
\hline \multirow{2}{*}{$\begin{array}{l}\mathrm{Hb} \\
(\mathrm{g} / \mathrm{dl})\end{array}$} & Water & $15.3 \pm 1.1$ & $15.9 \pm 0.9^{*}$ & $15.4 \pm 0.7$ & $\mathrm{~F}=2.91$ \\
\hline & OS-1 & $15.5 \pm 0.8$ & $16.1 \pm 0.7^{*}$ & $15.1 \pm 1.2$ & $p=0.08$ \\
\hline \multirow{2}{*}{$\begin{array}{l}\text { Osmolarity } \\
\left(\mathrm{mOsm} / \mathbf{k g ~ H} \mathrm{H}_{2} \mathrm{O}\right)\end{array}$} & Water & $290.9 \pm 5.4$ & $296.2 \pm 3.5^{\star}$ & $285.0 \pm 3.4^{*}$ & $F=7.73$ \\
\hline & OS-1 & $292.3 \pm 5.4$ & $296.2 \pm 3.5^{\star}$ & $294.0 \pm 2.8$ & $P=0.004 \dagger$ \\
\hline \multirow{2}{*}{$\begin{array}{l}\text { Sodium } \\
\text { (mmol/L) }\end{array}$} & Water & $141.7 \pm 1.5$ & $142.3 \pm 1.9$ & $138.4 \pm 1.7^{\star}$ & $F=33.85$ \\
\hline & OS-1 & $141.8 \pm 0.9$ & $142.6 \pm 1.4$ & $141.8 \pm 1.0$ & $P=0.001 \dagger$ \\
\hline \multirow{2}{*}{$\begin{array}{l}\text { Potassium } \\
(\mathrm{mmol} / \mathrm{L})\end{array}$} & Water & $4.5 \pm 0.4$ & $4.4 \pm 0.3$ & $4.0 \pm 0.4^{*}$ & $F=1.51$ \\
\hline & OS-1 & $4.5 \pm 0.4$ & $4.4 \pm 0.4$ & $4.2 \pm 0.4$ & $p=0.24$ \\
\hline \multirow{2}{*}{$\begin{array}{l}\text { Magnesium } \\
(\mathrm{mmol} / \mathrm{L})\end{array}$} & Water & $0.88 \pm 0.02$ & $0.87 \pm 0.02$ & $0.84 \pm 0.02^{*}$ & $F=1.35$ \\
\hline & OS-1 & $0.88 \pm 0.04$ & $0.86 \pm 0.04$ & $0.85 \pm 0.05^{*}$ & $p=0.28$ \\
\hline \multirow{2}{*}{$\begin{array}{l}\text { Chloride } \\
\text { (mmol/L) }\end{array}$} & Water & $101.0 \pm 1.1$ & $102.6 \pm 2.3^{*}$ & $99.5 \pm 2.1^{*}$ & $F=19.51$ \\
\hline & OS-1 & $101.9 \pm 1.3$ & $103.7 \pm 1.5^{\star}$ & $103.3 \pm 1.5^{\star}$ & $P=0.001 \dagger$ \\
\hline
\end{tabular}

*significant $(p<0.05)$ difference from the prevalue.

†significant $(p<0.05)$ difference between conditions.

DHR, downhill running; Hb, haemoglobin; Hct, haematocrit.

\section{RESULTS}

\section{Downhill running}

To reduce the $2 \%$ of body mass, three participants ran for $40 \mathrm{~min}$, two for $50 \mathrm{~min}$ and five for $60 \mathrm{~min}$ for both conditions. The distance covered in the time was $5.4-8.4 \mathrm{~km}$, and the average velocity was $7.9 \pm 1.2 \mathrm{~km} / \mathrm{h}$. The amount of body mass loss at immediately after exercise, thus the amount of the fluid intake was 1140-1600 $(1324 \pm 17) \mathrm{ml}$ for the water and $1100-1500(1285 \pm 17) \mathrm{ml}$ for the OS- $1^{\circledR}$ condition.

The average HR, RPE and thermal sensation during DHR were $159.1 \pm 3.0 \mathrm{bpm}, 5.9 \pm 0.9$ and $13.0 \pm 2.0$, respectively, without a significant difference between conditions. Systolic blood pressure increased and diastolic blood pressure decreased by approximately $10 \mathrm{~mm} \mathrm{Hg}$ from the baseline during DHR. The tympanic temperature increased by $2^{\circ} \mathrm{C}$ from the baseline $\left(36.6^{\circ} \mathrm{C} \pm 0.2^{\circ} \mathrm{C}\right)$ during DHR for both conditions.

As shown in table 1, no significant differences were found for the baseline values of $\mathrm{Hct}, \mathrm{Hb}$ and serum osmolality between the water and OS- ${ }^{\circledR}$ conditions. Immediately after DHR, Hct, $\mathrm{Hb}$ and serum osmolality increased significantly for both conditions similarly, and returned to the baseline values at $80 \mathrm{~min}$ post-DHR.

\section{Changes in TF}

Figure 2 shows the changes in TF following DHR. No significant difference was found for the baseline TF between the water $(25.1 \pm 1.5 \mathrm{~Hz})$ and OS- ${ }^{\circledR}(25.2 \pm 1.3$ $\mathrm{Hz}$ ) conditions. TF did not change significantly at immediately after DHR for both conditions (24.6 \pm 2.1 and $24.7 \pm 1.4 \mathrm{~Hz}$, respectively). Changes in TF were significantly different between the conditions such that at $30 \mathrm{~min}$ after water intake (50 min post-DHR), TF decreased by $4.3 \mathrm{~Hz}$ from the baseline, but TF increased by $3.7 \mathrm{~Hz}$ after OS- $1^{\circledR}$ ingestion. At $80 \mathrm{~min}$ after DHR, TF was still lower than the baseline for the water condition $(20.0 \pm 1.6 \mathrm{~Hz})$ but higher for the OS- $1^{\circledR}$ condition $(30.6 \pm 4.8 \mathrm{~Hz})$.

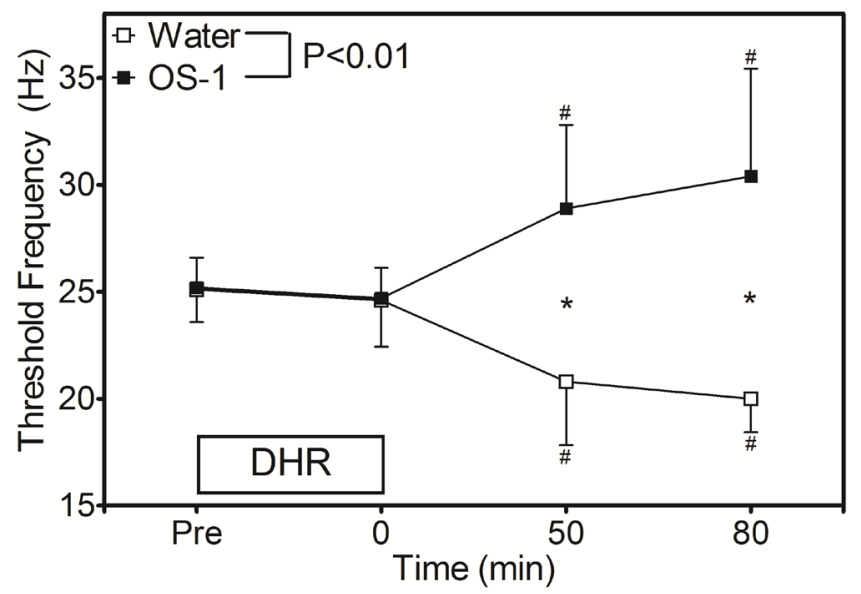

Figure 2 Changes in threshold frequency of electrical train simulation to induce muscle cramp before (pre), immediately after (0), and 50 and $80 \mathrm{~min}$ after DHR in the heat for water and OS $-1{ }^{\circledR}$ intake conditions. A significant $(p<0.01)$ interaction effect was found. * indicates a significant $(p<0.05)$ different from the baseline (pre) value. \# indicates a significant $(p<0.05)$ difference between the conditions. DHR, downhill running. 


\section{Changes in serum electrolytes concentrations}

As shown in table 1, a significant interaction effect was found for the changes in serum sodium and chloride concentrations, and post-hoc analyses showed significantly lower values at $80 \mathrm{~min}$ post-DHR (60 min after fluid ingestion) for the water than OS- ${ }^{\circledR}$ condition. Serum chloride concentration increased significantly from baseline to immediately post-DHR for both conditions, without a significant difference between them. Serum potassium concentration decreased for the water condition only, and serum magnesium concentration decreased from baseline to $80 \mathrm{~min}$ post-DHR for both conditions similarly.

\section{DISCUSSION}

The results of the present study showed that (1) dehydration itself did not change the TF as previous studies reported, ${ }^{8-10}(2)$ spring water intake after dehydration decreased TF, which is an indicative of increased muscle cramp susceptibility, (3) ingestion of fluid containing electrolytes $\left(\mathrm{OS}-1^{\circledR}\right)$ increased $\mathrm{TF}$, showing muscles became less susceptible to cramp and (4) serum sodium and chloride concentrations were decreased after spring water intake, but maintained after OS- $1^{\circledR}$ intake. It appears that dilution of electrolytes was a cause of the increased muscle cramp susceptibility.

In the previous studies that investigated the effects of dehydration on muscle cramp, serum sodium concentration was increased, ${ }^{910}$ and they found no changes in $\mathrm{TF}$ of electrical stimulation to induce muscle cramp at immediately after 3\%-5\% dehydration. In the present study, no significant changes in serum electrolyte concentrations were observed after $2 \%$ dehydration induced by DHR in the heat. This may be due to the lower dehydration level $(2 \%)$ than that of the previous studies $(3 \%-5 \%)$. In fact, the increases in $\mathrm{Hct}$ and $\mathrm{Hb}$ at immediately after exercise were smaller in the present study (table 1), when compared with those in the previous studies. ${ }^{910}$ It is possible that sodium, chloride and other electrolytes were lost with sweat, but because the decrease in plasma volume was proportional to that of the electrolytes, no changes in the electrolytes concentrations were observed. To the best of our knowledge, this was the first study to examine changes in TF for more than 30 min after dehydration and water intake, and show that TF decreased at 30 and 60 min after spring water intake (figure 2). The magnitude of the decrease in TF in the present study $(4-5 \mathrm{~Hz})$ was comparable to the previous study $^{15}$ in which an increase in muscle cramp susceptibility was found after volitionally induced muscle cramp $(\sim 4 \mathrm{~Hz})$. It is not known how long this effect would last, so it is important to extend the TF measures to 2 hours or longer after water intake in the future studies.

It is interesting that TF increased at 30 and $60 \mathrm{~min}$ after ingesting OS- $1^{\circledR}$ (figure 2). This was not expected, since we hypothesised that TF would not change for the OS- $1{ }^{\circledR}$ condition. The magnitude of the TF increase $(\sim 4$ to $5 \mathrm{~Hz}$ ) in the present study was similar to that found after a neuromuscular electrical stimulation intervention for 6 weeks to reduce calf muscle cramp. ${ }^{16}$ To the best of our knowledge, this was the first study to show that ORS intake may reduce muscle cramp. It should be noted that serum sodium and chloride concentrations did not increase after OS- $1^{\circledR}$ intake. This suggests that the increase in TF was not directly associated with serum sodium and chloride concentrations, although they showed a significant difference between the water and OS- $1^{\circledR}$ conditions (table 1 ). It is important to note that OS- $1^{\circledR}$ contains glucose $(18300 \mathrm{mg} / \mathrm{L})$; thus, it might have been better to add the same amount of glucose to spring water to examine the effects of glucose on muscle cramp. If the electrolytes in OS-1 were the main reason for the increase in TF, judging from the differences in serum electrolytes concentrations between the OS- $1^{\circledR}$ and water conditions (table 2), it appears that sodium and chloride are more important than potassium and magnesium. Further studies are necessary to investigate the mechanisms of the increased TF after OS- ${ }^{\circledR}$ intake.

The main reason for the choice of DHR in the present study was that metabolic demand is smaller during DHR than level or uphill running ${ }^{19}$ but it still induces a lot of sweating when it is performed in the heat. It has been documented that increased excitatory afferent activity due to increased muscle spindle activity and decreased inhibitory afferent activity due to decreased Golgi tendon activity lead to increased alpha motor neuron activity, increasing muscle membrane activity, inducing muscle cramp. ${ }^{1-4}$ DHR has been known to induce muscle damage due to eccentric (lengthening) muscle contractions. ${ }^{20}$ Thus, it was thought that muscle spindle and Golgi tendon organs might be more affected by eccentric (lengthening) muscle contractions performed in DHR. It is interesting to investigate further the effects of eccentric muscle contractions on EAMC in comparison to concentric (shortening) muscle contractions.

The present study showed a possibility that intake of OS- $1^{\circledR}$ before and during exercise would reduce EAMC. To investigate this, it is necessary to establish a reliable marker of muscle cramp susceptibility during exercise. It is also important to understand the relationship between TF and actual muscle cramp. Even if the cause of EAMC is more associated with neural especially spinal mechanisms, it is likely that dilution of electrolytes is also involved in the mechanisms directly or indirectly. ${ }^{1}$ It is

\section{What this study adds}

Water intake after dehydration with exercise makes muscles more susceptible to muscle cramp.

- Oral rehydration solution (ORS) intake after dehydration with exercise makes muscles less likely to cramp.

- It seems possible that dilution of electrolytes especially sodium and chloride in the body may increase muscle cramp susceptibility.

- Ingestion of ORS instead of water during and after exercise may reduce exercise-associated muscle cramp. 
also interesting to know whether the findings of our study will apply to other muscle cramps such as those affecting older people and pregnant women. We conclude that the involvement of electrolytes in EAMC should not be ignored.

Acknowledgements The authors appreciate the participants of the studies.

Contributors KN designed the study, the data collection was performed mainly by WYL and HK, and the data analyses were done by WYI and KN. KN drafted the manuscript and the final manuscript was checked by all authors.

Funding The authors appreciate the support from the Otsuka Pharmaceutical Factory Incorporation (Japan), which provided us a grant and OS-1® to perform the study. However, this manuscript was not oversighted by the company.

Competing interests None declared.

Patient consent for publication Obtained.

Provenance and peer review Not commissioned; externally peer reviewed.

Open access This is an open access article distributed in accordance with the Creative Commons Attribution Non Commercial (CC BY-NC 4.0) license, which permits others to distribute, remix, adapt, build upon this work non-commercially, and license their derivative works on different terms, provided the original work is properly cited, appropriate credit is given, any changes made indicated, and the use is non-commercial. See: http://creativecommons.org/licenses/by-nc/4.0/.

\section{REFERENCES}

1. Schwellnus MP. Cause of exercise associated muscle cramps (EAMC)--altered neuromuscular control, dehydration or electrolyte depletion? Br J Sports Med 2009;43:401-8.

2. Minetto MA, Holobar A, Botter A, et al. Mechanisms of CRAMP contractions: peripheral or central generation? J Physiol 2011;589:5759-73.

3. Nelson NL, Churilla JR. A narrative review of exercise-associated muscle cramps: factors that contribute to neuromuscular fatigue and management implications. Muscle Nerve 2016;54:177-85.

4. Swash M, Czesnik D, de Carvalho M. Muscular cramp: causes and management. Eur J Neurol 2019;26:214-21.

5. Schwellnus MP, Nicol J, Laubscher R, et al. Serum electrolyte concentrations and hydration status are not associated with exercise associated muscle cramping (EAMC) in distance runners. $\mathrm{Br} J$ Sports Med 2004;38:488-92.

6. Hoffman MD, Stuempfle KJ. Muscle cramping during a 161-km ultramarathon: comparison of characteristics of those with and without cramping. Sports Med Open 2015;1.

7. Giuriato G, Pedrinolla A, Schena F, et al. Muscle cramps: a comparison of the two-leading hypothesis. J Electromyogr Kinesiol 2018;41:89-95

8. Schwellnus MP, Drew N, Collins M. Increased running speed and previous cramps rather than dehydration or serum sodium changes predict exercise-associated muscle cramping: a prospective cohort study in 210 Ironman triathletes. Br J Sports Med 2011;45:650-6.

9. Miller KC, Mack GW, Knight KL, et al. Three percent hypohydration does not affect threshold frequency of electrically induced cramps. Med Sci Sports Exerc 2010;42:2056-63.

10. Braulick KW, Miller KC, Albrecht JM, et al. Significant and serious dehydration does not affect skeletal muscle cramp threshold frequency. Br J Sports Med 2013;47:710-4.

11. Adrogué HJ, Madias NE. Hyponatremia. N Engl J Med 2000;342:1581-9.

12. Jung AP, Bishop PA, Al-Nawwas A, et al. Influence of hydration and electrolyte supplementation on incidence and time to onset of exercise-associated muscle cramps. J Athl Train 2005;40:71-5.

13. Minetto MA, Botter A, Ravenni R, et al. Reliability of a novel neurostimulation method to study involuntary muscle phenomena. Muscle Nerve 2008;37:90-100.

14. Panza G, Stadler J, Murray D, et al. Acute passive static stretching and cramp threshold frequency. J Athl Train 2017;52:918-24.

15. Miller KC, Long BC, Edwards JE. Muscle cramp susceptibility increases following a volitionally induced muscle cramp. Muscle Nerve 2017;56:E95-E99.

16. Behringer M, Harmsen J-F, Fasse A, et al. Effects of neuromuscular electrical stimulation on the frequency of skeletal muscle cramps: a prospective controlled clinical trial. Neuromodulation 2018;21:815-22.

17. Borg GAV. Psychophysical bases of perceived exertion. Med Sci Sports Exerc 1982;14:377???381-81

18. Young AJ, Sawka MN, Epstein Y, et al. Cooling different body surfaces during upper and lower body exercise. J Appl Physiol 1987;63:1218-23.

19. Minetti AE, Moia C, Roi GS, et al. Energy cost of walking and running at extreme uphill and downhill slopes. J Appl Physiol 2002;93:1039-46.

20. Chen TC, Nosaka K, Tu JH. Changes in running economy following downhill running. J Sports Sci 2007;25:55-63. 


\section{Correction: Water intake after dehydration makes muscles more susceptible to cramp but electrolytes reverse that effect}

Lau WY, Kato H, Nosaka K. Water intake after dehydration makes muscles more susceptible to cramp but electrolytes reverse that effect. BMJ Open Sport E Exercise Medicine 2019;5:e00478. doi: 10.1136/bmjsem-2018-000478

The authors want to alert readers to the following error identified in the published version.

Under the Experimental design section (paragraph 2, line 1), due to incorrect electrolyte value, the text has been updated as below:

OS-1 contains sodium (1150 mg/L), potassium (780 mg/L), magnesium (24 mg/L), chloride (1770 mg/L), glucose (18 $000 \mathrm{mg} / \mathrm{L})$ and others (eg, phosphorus).

Open access This is an open access article distributed in accordance with the Creative Commons Attribution Non Commercial (CC BY-NC 4.0) license, which permits others to distribute, remix, adapt, build upon this work non-commercially, and license their derivative works on different terms, provided the original work is properly cited, appropriate credit is given, any changes made indicated, and the use is non-commercial. See: http://creativecommons.org/licenses/by-nc/4.0/.

C Author(s) (or their employer(s)) 2019. Re-use permitted under CC BY-NC. No commercial re-use. See rights and permissions. Published by BMJ.

BMJ Open Sport Exerc Med 2019;5:000478corr1. doi:10.1136/bmjsem-2018-000478corr1

Check for updates 